\title{
Eine methodische Vereinfachung der mechanisierten Bilirubin-, Serumeiweiß- und Liquoreiweißbestimmung
}

\author{
Von H. KaEhLER und J. WeiLAND
}

Aus dem Chemischen Institut des Städtischen Krankenbauses Berlin-Neukölln

(Eingegangen am 4. Juni/30. Juli 1973)

Es wird das Vorgehen beschrieben, Bilirubin und Eiweiß im Serum bzw. Plasma sowie Eiweiß im Liquor cerebrospinalis mit dem Autoanalyzer zu bestimmen, ohne das Schlauchsystem zu ändern oder einen Filterwechsel vornehmen zu müssen. Das Umstellen von einer Methode auf eine andere dauert weniger als $15 \mathrm{~min}$. Vergleichende manuelle Bestimmungen beweisen die Zuverlässigkeit der mechanisierten Methoden. Für manuelle und mechanisierte Bestimmungsverfahren wird ein Bewertungskriterium angegeben.

\section{A simplified determination of bilirubin and protein in serum, plasma and liquor cerebrospinalis}

The procedure for the determination of bilirubin and protein in serum, or blood plasma, and of protein in liquor cerebrospinalis by the Autoanalyzer without changing the tube system or exchanging the filters is described. Changing from one method to the other takes less than $15 \mathrm{~min}$. A comparison with manual detcrminations showed the reliability of the mechanized methods. Criteria of suitability for the manual and mechanical analytical methods are given.

Der Einsatz mechanisierter Bestimmungsmethoden im klinischen Laboratorium scheitert häufig am Kostenund Platzbedarf, mit dem die Aufstellung von Analysen„automaten" verbunden ist. Der Aufwand kann jedoch gering gehalten werden, wenn ein solcher Analysator für mehrere Bestimmungen einsetzbar ist.

Im folgenden wird die Technologie angegeben, auf einem ursprünglich für die Serumbilirubinbestimmung eingerichteten Autoanalyzer ${ }^{1}$ ), den Gesamteiweißgehalt in Serum, Plasma und Liquor cerebrospinalis $\mathrm{zu}$ bestimmen, ohne dabei das Schlauchsystem zu ändern oder die Interferenzfilter und die Blende für den Vergleichsstrahl austauschen zu müssen. Die erforderliche „Umrüst" zeit beträgt weniger als $15 \mathrm{~min}$ für das Durchspülen des Schlauchsystems mit den neuen Reagenzien; es ist allein die Basislinie nachzustellen.

1) Hersteller: Technicon $\mathrm{GmbH}$, Bad Vilbel.
Die Meßergebnisse werden mit den Befunden manueller Untersuchungstechniken verglichen.

\section{Material und Methoden}

Die mechanisierten Bestimmungen wurden auf einem 1-KanalAutoanalyzer (Untersuchungsfrequenz: 50 Proben/h, Waschzeit: Probenansaugzeit $=2: 1$, Papiervorschub: $7,8 \mathrm{~mm} / \mathrm{min}$ ) durchgeführt. Die Förderleistungen des Schlauchsystems, die verwendeten Reagenzlösungen sowie die Reihenfolge der Reagenzieneinspeisung sind im Fließschema (Abb. 1) dargestellt.

Dic Bilirubinbestimmungen erfolgten nach der Methode von JeNDRASSIK und GróF (1); mechanisiert in Anlehnung an die Technicon-Vorschrift (2), manuell unter Verwendung des Reagenziensatzes „Merckotest 3333 Bilirubin“(2).

Die Plasma- und Serumeiweißbestimmungen wurden mechanisiert nach der Biuretmethode (3) und manuell refraktometrisch durchgeführt.

2) Hersteller: E. Merck, Darmstadt.

\begin{tabular}{|c|c|c|c|}
\hline $\begin{array}{l}\text { Gesomt- } \\
\text { bilirubin }\end{array}$ & $\begin{array}{c}\text { Gesamteiweiß } \\
\text { im Serum }\end{array}$ & $\begin{array}{l}\text { Gesomteiweiß } \\
\text { im Liquor }\end{array}$ & $\begin{array}{l}\text { direkles } \\
\text { Bilirubin }\end{array}$ \\
\hline $\begin{array}{l}\text { Diazotierungs- } \\
\text { gemisch }\end{array}$ & Arbeitslösung & & $\begin{array}{l}\text { Diazotierungs- } \\
\text { gemisch }\end{array}$ \\
\hline Luft & Luft & Luft & Luft \\
\hline Accelerator & Arbeitslösung & Biuretlösung & Solzsöure \\
\hline Probe & Probe & Probe & Probe \\
\hline Ascorbinsäure & Arbeitslösung & Folin & Ascorbinsäure \\
\hline Tariratpuffer & Arbeitslösung & Natronlauge & Tartralpuffer \\
\hline $\begin{array}{l}\text { Wosser für } \\
\text { Sompler }\end{array}$ & $\begin{array}{l}\text { Wasser für } \\
\text { Sampler }\end{array}$ & $\begin{array}{l}\text { Wosser für } \\
\text { Sompler }\end{array}$ & $\begin{array}{l}\text { Wasser für } \\
\text { Sampler }\end{array}$ \\
\hline von Küvelte & von Küvetle & von Küvette & von Küvette \\
\hline
\end{tabular}

Sampler IV

$1: 2$

Abb. 1

Fließschema für die mechanisierte Bilirubin-, Liquoreiweiß- und Serum-/Plasmaeiweißbestimmung 
Dic Liquoreiweißbestimmungen exfolgten mit FoLIN'schem Phenolreagenz $(4,5,6)$ entsprechend unserer manuellen Standardmethode:

$0,5 \mathrm{ml} \mathrm{Liquor}$ mit $3,5 \mathrm{ml} 100 \mathrm{~g} / 1 \quad \mathrm{Na}_{2} \mathrm{CO}_{3}$-Lösung und $0,5 \mathrm{ml}$ $1 \mathrm{~g} / 1 \mathrm{CuSO}_{4}$-Lösung mischen. Nach $30 \mathrm{~min}$ (Raumtemperatur) $0,5 \mathrm{ml}$ Folin-Ciocalteu-Reagenz (Merck Nr. 9001, $1+1 \mathrm{mit}$ dest. Wasser vorverdünnt) zugeben, $5 \mathrm{~min}$ auf $37^{\circ} \mathrm{C}$ erwärmen und bei $578 \mathrm{~nm}$ die Extinktion gegen Reagenzienleerwert messen.

Bei der mechanisierten Liquoreiweißbestimmung wird in stärker basischem Milieu $(0,5 \mathrm{~mol} / 1 \mathrm{NaOH})$ eine wesentliche Vergrößerung der Peakhöhen erreicht; als Detergenz ist Tween 40 geeignet, da Brij 35 starke Trübungen mit dem Phenolreagenz hervorruft.

Zur Registrierung ${ }^{3}$ ) der Absorptionsspektren der Chromophore (Abb. 2) wurden entspr. dem Fließschema (Abb. 1) für jede Methode die einzusetzenden Chemikalien und Proben manuell gemischt.

\section{Reagenzien}

1 Gesamtbilirubin

1.1 Accelerator: In $400 \mathrm{ml}$ dest. Wasser von 50 bis $60^{\circ} \mathrm{C}$ werden $17 \mathrm{~g}$ Coffein, $25 \mathrm{~g}$ Natriumbenzoat und $42 \mathrm{~g}$ Natriumacetat gelöst und nach dem Abkühlen mit dest. Wasser zu $1000 \mathrm{ml}$ aufgefüllt.

1.2 Sulfanilsäure: $10 \mathrm{~g}$ Sulfanilsäure werden in $500 \mathrm{ml}$ dest. Wasser und $15 \mathrm{ml}$ konz. Salzsäure $(\mathrm{d}=1,15)$ gelöst und mit dest. Wasser zu $1000 \mathrm{ml}$ aufgefüllt.

1.3 Natriumnitrit: $0,5 \mathrm{~g} \mathrm{NaNO}_{2}$ mit dest. Wasser zu $100 \mathrm{ml}$ lösen.

1.4 Diazotierungsgemisch: $200 \mathrm{ml}$ Lösung $1.2 \mathrm{mit} 20 \mathrm{ml}$ Lösung 1.3 mischen.

1.5 Tartratpuffer: $50 \mathrm{~g} \mathrm{NaOH}$ und $175 \mathrm{~g}$ Kaliumnatriumtartrat $4 \mathrm{H}_{2} \mathrm{O}$ werden mit dest. Wasser zu $1000 \mathrm{ml}$ gelöst.

1.6 Ascorbinsäure: $40 \mathrm{~g}$ Ascorbinsäure werden mit dest. Wasser zu $1000 \mathrm{ml}$ gelöst.

2 Direkt reagierendes Bilirubin

Es werden die Reagenzien der Gesamtbilirubinbestimmung verwendet, jedoch wird die Acceleratorlösung 1.1 ersetzt durch $2.10,05 \mathrm{~mol} / 1$ Salzsäure.

3 Plasma- und Serumeiweiß

3.1 Alkalische Jodidlösung: $8 \mathrm{~g} \mathrm{NaOH}$ und $5 \mathrm{~g} \mathrm{KJ}$ werden mit dest. Wasser zu $1000 \mathrm{ml}$ gelöst.

3.2 Biuretlösung: In $500 \mathrm{ml}$ dest. Wasser werden nacheinander $45 \mathrm{~g}$ Kaliumnatriumtattrat $\cdot 4 \mathrm{H}_{2} \mathrm{O}, 15 \mathrm{~g} \mathrm{CuSO}_{4} \cdot 5 \mathrm{H}_{2} \mathrm{O}$ und 5 g KJ gelöst. Nach Zugabe von $100 \mathrm{ml} 2 \mathrm{~mol} / \mathrm{l} \mathrm{NaOH}$ wird die Lösung mit dest. Wasser zu $1000 \mathrm{ml}$ aufgefüllt.

3.3 Arbeitslösung: $800 \mathrm{ml}$ Lösung $3.1 \mathrm{mit} 200 \mathrm{ml}$ Lösung 3.2 mischen.

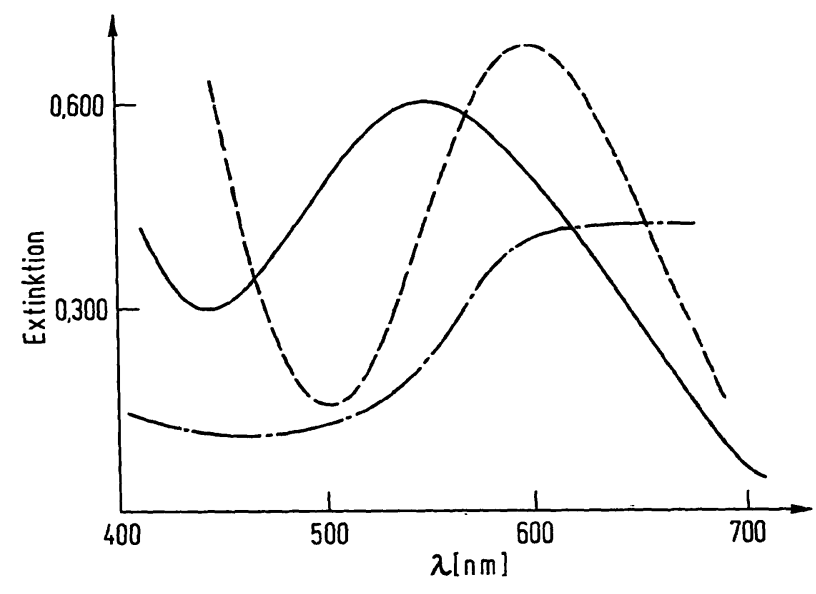

Abb. 2

Absorptionsspektren der Chromophore der Bilirubin- (----), Liquoreiweiß- (-.....) und Serumeiweiß-( $(-)$ bestimmungen "

3) Unicam SP 1800 der Philips GmbH, Hamburg.
3.4 Leerlösung: $9 \mathrm{~g}$ Kaliumnatriumtarttat $\cdot 4 \mathrm{H}_{2} \mathrm{O}$ werden mit Lösung $3.1 \mathrm{zu} 1000 \mathrm{ml}$ gelöst. (3.4 ist zur Ermittlung der Probenleerwerte anstelle der Lösung $3.3 \mathrm{zu}$ verwenden.)

4 Liquoreiweiß

4.1 Biuretlösung: $0,8 \mathrm{~g}$ Kaliumnatriumtartrat $\cdot 4 \mathrm{H}_{2} \mathrm{O}$ und $0,4 \mathrm{~g}$ $\mathrm{CuSO}_{4} \cdot 5 \mathrm{H}_{2} \mathrm{O}$ werden in $500 \mathrm{ml}$ dest. Wasser gelöst. Nach Zugabe von $100 \mathrm{ml} 0,5 \mathrm{~mol} / 1 \mathrm{NaOH}$ wird die Lösung mit dest. Wasser zu $1000 \mathrm{ml}$ aufgefüllt.

4.2 Folin-Phenol-Reagenz: Die Stammlösung (z. B. Merck Nr. 9001) wird $1+1$ mit dest. Wasser verdünnt.

$4.30,5 \mathrm{~mol} / 1 \mathrm{NaOH}$.

\section{Justierlösungen}

Die Justierlösungen wurden für die Bilirubinbestimmungen in den Konzentrationen 7,0 bis $150,0 \mathrm{mg} / 1 \bumpeq 12$ bis $256 \mu \mathrm{mol} / \mathrm{l}$ aus einem Kontrollserum ${ }^{4}$ ) und für die. Serum-/Plasmaeiweißbestimmungen in den Konzentrationen 20 bis $100 \mathrm{~g} / \mathrm{l}$ bzw. für die Liquoreiweißbestimmungen (über eine Stammlösung mit $2,0 \mathrm{~g} / 1$ Albumin) im Konzentrationsbereich von 0,1 bis $1,2 \mathrm{~g} / 1$ aus einem Albumin-Stock ${ }^{5}$ ) täglich frisch hergestellt.

\section{Ergebnisse und Diskussion}

Probenfrequenz und die gegenüber den meisten Standardverfahren (2) verlängerte Waschphase des Fließsystems (Abb. 1) führen zu einer Trennung der aufeinanderfolgenden Peaks, die keine Berücksichtigung von Verschleppungseffekten bei der Auswertung erfordert.

Die halblogarithmisch dargestellten Bezugsfunktionen verlaufen bis $z \mathrm{u}$ den höchsten eingesetzten Konzentrationen linear und dienten zur Auswertung aller Meßergebnisse.

Die Bestimmungen der Präzision in der Serie und von Tag $\mathrm{zu}$, Tag sind in Tabelle 1 zusammengestellt. Als Vergleichșmethoden dienten eine manuelle Vorschrift (8) bei der Bilirubinbestimmung, beim Serumeiweiß die refraktometrische Bestimmung und bei der Liquoreiweißbestimmung eine manuelle Technik (vgl. oben). Innerhalb einer Serie und von Tag zu Tag liegen die Präzisionen der mechanisierten Verfahren beim Liquoreiweiß und beim Gesamtbilirubin über den Präzisionen der manuellen Methoden; bei der Serum-

Tab. 1

Präzision innerhalb einer Serie und von Tag zu Tag bei mechanisierter und manueller Bestimmung von Gesamtbilirubin, Serumeiwei $\beta$ und Liquoreiweiß bei $590 \mathrm{~nm}$

\begin{tabular}{|c|c|c|c|}
\hline & $\begin{array}{l}\text { Gesamt- } \\
\text { bilirubin }\end{array}$ & $\begin{array}{l}\text { Eiweiß im } \\
\text { Serum }\end{array}$ & $\begin{array}{l}\text { Eiweiß im } \\
\text { Liquor }\end{array}$ \\
\hline \multicolumn{4}{|c|}{$\begin{array}{c}\text { Präzision } \\
\text { innerhalb einer Serie }\end{array}$} \\
\hline Autoanalyzer VK & $\begin{array}{c}1,0 \% \\
(n=15)\end{array}$ & $\begin{array}{c}1,5 \% \\
(n=15)\end{array}$ & $\begin{array}{c}1,2 \% \\
(n=17)\end{array}$ \\
\hline $\begin{array}{c}\text { Handmethode VK } \\
\text { Präzision } \\
\text { von Tag zu Tag }\end{array}$ & $\begin{array}{c}\text { Präzision } \\
\text { von Tag zu Tag }\end{array}$ & $\begin{array}{c}0,8 \% \\
(n=15)\end{array}$ & $\begin{array}{c}2,2 \% \\
(n=17)\end{array}$ \\
\hline Autoanalyzer VK & $\begin{array}{c}2,0 \% \\
(n=15)\end{array}$ & $\begin{array}{c}2,9 \% \\
(n=15)\end{array}$ & $\begin{array}{c}2,5 \% \\
(n=15)\end{array}$ \\
\hline Handmethode VK & $\begin{array}{c}3,9 \% \\
(n=15)\end{array}$ & $\begin{array}{c}1,5 \% \\
(n=15)\end{array}$ & $\begin{array}{c}4,3 \% \\
(n=15)\end{array}$ \\
\hline
\end{tabular}

4) Bilirubin Control der Firma Dade, München.

5) Formula T 23-0204 der Firma Technicon, Bad Vilbel. 
eiweißbestimmung ist dagegen - in Ubereinstimmung mit den Angaben von Doerr und Stamm (7) - die Handmethode dem mechanisierten Verfahren überlegen, auch die ermittelten Variationskoeffizienten entsprechen den Literaturangaben (9).

Der Vergleich statistischer Größen (10) erlaubt Aussagen über die Qualität von Analysensystemen. Wir verwenden als geeigneten Indikator den Analysatorquotienten $\mathrm{AQ}$, der für Konzentrationen im sog. klinischen Normalbereich definiert ist $\mathrm{zu}$ :

$$
\mathrm{AQ}=\frac{\mathrm{VK} \text { der Messung in Serie }}{\mathrm{VK} \text { der Messung von Tag zu Tag }} \cdot 100 .
$$

AQ sollte für gute - auch manuelle - Arbeitsplätze nur wenig unter 50 absinken. Der Quotient wird sich dem Grenzwert 100 nähern, je besser die mechanisierten Systeme individuelle Fehler des Bedienungspersonals und apparative Inkonstanzen eliminieren.

Aus den Angaben der-Tabelle 1 errechnen sich Analysatorquotienten zwischen 48 und 54. Am AQ-Kriterium geprüft, verringert die Fließsystemtechnik - trotz im allgemeinen verbesserter Präzisionen - den Störeinfluß äußerer Bedingungen nicht in dem gewünschten Maße. Wir führen dies auf das unterschiedliche Nachlassen der Schlauchelastizität, auf einen unterschiedlichen Füllungsgrad der Probenbecher sowie auf Temperatureinflüsse und Störungen im Strömungsprofil während der langen Verweilzeit im System zurück.

Der Vergleich zwischen den mechanisierten und manuellen Untersuchungsverfahren wird durch Korrelationsbetrachtungen (Berechnung der Regressionsfunktion $\mathrm{y}=\mathrm{a}+\mathrm{b} \cdot \mathrm{x}$ ) möglich. Ihre Äquivalenz wird durch den Korrelationskoeffizienten $\mathrm{r}$ ausgedrückt, der bei sich völlig entsprechenden Verfahren zu 1 wird. Die Konstanten der Regressionsfunktionen und die Korrelationskoeffizienten in Tabelle 2 zeigen eine gute Äquivalenz der angewandten Methoden.

VK und Korrelationskoeffizient der Serumeiweißbestimmung bei Messungen außerhalb des Absorptionsmaximums des Chromophors (Abb. 2) fallen deutlich ab:

bei $550 \mathrm{~nm}: \mathrm{n}=15, \overline{\mathrm{x}}=77,7 \mathrm{~g} / \mathrm{l}, \mathrm{s}=0,79 \mathrm{~g} / \mathrm{l}$,

$\mathrm{VK}=1,0 \%$

bei $590 \mathrm{~nm}: \mathrm{n}=15, \overline{\mathrm{x}}=78,3 \mathrm{~g} / \mathrm{l}, \mathrm{s}=1,17 \mathrm{~g} / 1$, $\mathrm{VK}=1,5 \%$.
Tab. 2

Konstanten der Regressionsgeraden und Korrelationskoeffizienten bei mechanisierter und manueller Bestimmung von Gesamtbilirubin, Serumeiweiß und Liquoreiweiß bei $590 \mathrm{~nm}$ bzw. $550 \mathrm{~nm}$

\begin{tabular}{|c|c|c|c|c|}
\hline & Anzahl & $a$ & b & $r$ \\
\hline \multicolumn{5}{|l|}{$\begin{array}{c}\text { Bilirubin im Serum } \\
(590 \mathrm{~nm})\end{array}$} \\
\hline $\begin{array}{c}\text { Autoanalyzer (x) } \\
\text { Handmethode (y) } \\
\text { Eiweiß im Liquor } \\
(590 \mathrm{~nm})\end{array}$ & 100 & $-1,43$ & 1,027 & 0,990 \\
\hline $\begin{array}{l}\text { Autoanalyzer }(x) \\
\text { Handmethode }(y)\end{array}$ & 99 & 0,01 & 0,934 & 0,987 \\
\hline $\begin{array}{l}\text { Eiweiß im Serum } \\
(590 \mathrm{~nm})\end{array}$ & & & & \\
\hline $\begin{array}{l}\text { Autoanalyzer }(y) \\
\text { Handmethode }(x)\end{array}$ & 92 & 0,40 & 0,976 & 0,967 \\
\hline \multicolumn{5}{|l|}{$\begin{array}{l}\text { Eiweiß im Serum } \\
(550 \mathrm{~nm})\end{array}$} \\
\hline $\begin{array}{l}\text { Autoanalyzer }(y) \\
\text { Handmethode }(x)\end{array}$ & 100 & 0,38 & 0,986 & 0,990 \\
\hline
\end{tabular}

Der Mittelwertunterschied ist nach dem t-Test (12) zufällig $(p=0,05)$ : die Zuverlässigkeit (Vertrauensbereiche) von Absorptionsmessungen wird durch die Verwendung sog. Routine-Einfach-Photometer (11) und durch Messungen an den Flanken eines Absorptionspeaks herabgesetzt.

Die Richtigkeit (10) der untersuchten Methoden wurde in der Serie und von Tag zu Tag unter Verwendung von Kontrollseren ${ }^{6}$ ) überprüft. Der Vergleich mit den tabellierten Werten des $t$-Tests $(p=0,05)$ zeigte für die gemessenen Abweichungen ( $<1,5 \%$ vom Sollwert) keine systematischen Fehler. Ein Kontrolliquor ${ }^{7}$ ) war zur Überprüfung ungeeignet, da sein Sollwert (Trübungsmessung) bis $\mathrm{zu} 17 \%$ niedriger lag als die ermittelten Werte. Bei guter Präzision ergab die refraktometrische Eiweißbestimmung - nicht jedoch die Biuretmethode - ähnlich hohe systematische Fehler, wenn Kontrollseren ${ }^{6}$ ) oder Albuminlösungen ${ }^{8}$ ) verwendet wurden.

Die vorgestellte methodische Vereinfachung der mechanisierten Bestimmung von Bilirubin, Liquor-, Plasmaund Serumeiweiß liefert präzise und - mit der zu fordernden Sicherheit - von systematischen Fehlern freie Meßwerte.

6) Monitrol I und II der Firma Dade, München.

7) Spinal Fluid Control der Firma Hyland, München.

8) Formula T 23-0204 der Firma Technicon, Bad Vilbel.

\section{Literatur}

1. JeNDRASSik, L. \& GRóF, P. (1938), Biochem. Z. 297, 81-89. 2. Technicon Autoanalyzer Methodology N-51.-3.WEICHSELBAUM, T. E. (1946), Amer. J. Clin. Pathol., Techn. Section 10, 40-49. - 4. Lowry, O. H. \& Rosebrough, N. J. (1951), J. Biol. Chem. 193, 265-275. - 5. Waldman, R. K. \& KRAUSE, L. A. (1953), J. Lab. Clin. Med. 42, 489-492. - 6. Daughaday, W. H. \& Lowry, O. H. (1952), J. Lab. Clin. Med. 39, 663-665. - 7. DoerR, P. \&
Stamir, D. (1968), diese Z. 6, 304-309. - 8. Klinisches Labor (1970), E. Merck, Darmstadt S. 103-108. - 9. NAZAR, S. M. \& SCHMIDT, H. (1972), diese Z. 10, 548-551. - 10. RICHTERICH, R., Greiner, R. \& KüfFer, H. (1973), diese Z. 11, 65-75. 11. von KLeIN-WISENBerg, A. (1973), Ätztl. Lab. 18, 243-252. 12. SACrs, L. (1968), Statistische Auswertungsmethoden, Springer Verlag Berlin, S. 140, 256.
Dr. H. Kachler Städt. Krankenhaus Neukölln Chemisches Institut 1 Berlin 47 Rudower Straße 56 